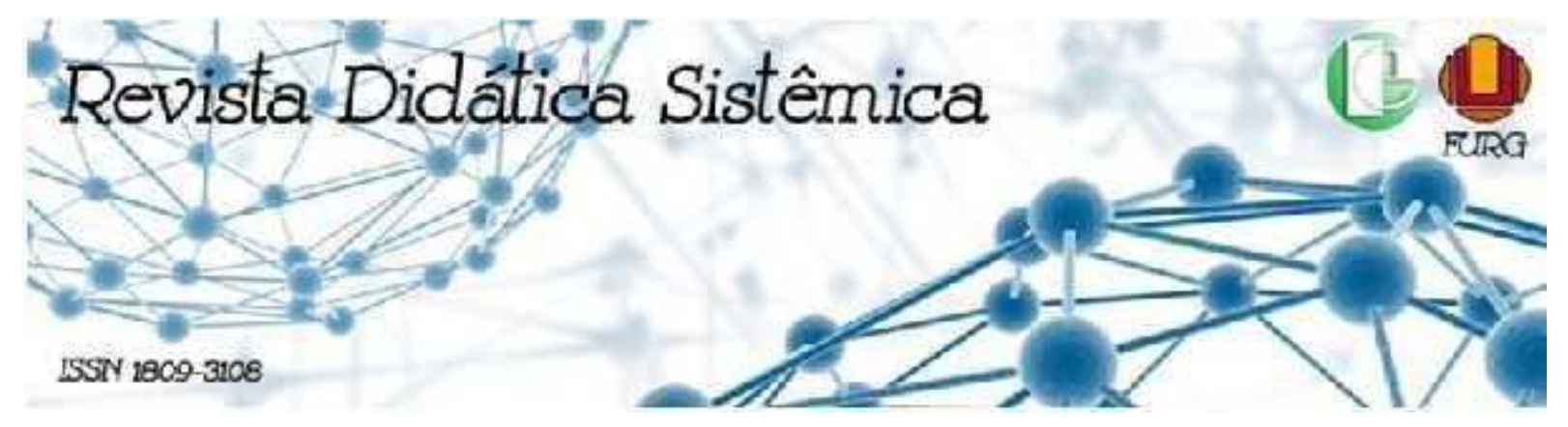

\title{
A ENGENHARIA DO CURRÍCULO: A EDUCAÇÃo FÍSICA NA ARTICULAÇÃo CURRICULAR COM A EDUCAÇÃO INFANTIL
}

\author{
Bethânia A. C. Zandomínegue ${ }^{1}$ \\ Vanessa Guimarães ${ }^{2}$ \\ Raquel F. M. Barbosa ${ }^{3}$
}

\begin{abstract}
RESUMO
Analisa os desafios e as possibilidades para a materialização do currículo articulado com a Educação Física na Educação Infantil, a partir do diálogo com diferentes linguagens, áreas do conhecimento e sujeitos da comunidade escolar. Utiliza a Pesquisa-Ação Colaborativa com atenção para as relações construídas com a equipe pedagógica, as professoras de sala, as famílias, as crianças, os bolsistas do Programa de Iniciação à Docência, a professora de Educação Física e a pesquisadora. Os dados oriundos de fotos, entrevistas, narrativas e diário de campo foram submetidos a um processo de análise interpretativa e articulados em uma rede de produção de sentidos e significados. Conclui que as mediações com a cultura popular, o Projeto Institucional e o Plano de Ação da Educação Física se constituíram engrenagens essenciais para a materialização de uma engenharia do currículo. Como entraves, destaca a resistência de algumas docentes ao trabalho colaborativo.
\end{abstract}

Palavras-chave: Pesquisa-Ação; Cultura popular; Criança; Currículo.

\section{CURRICULUM ENGINEERING: PHYSICAL EDUCATION IN THE CURRICULUM ARTICULATION WITH EARLY CHILDHOOD EDUCATION}

\begin{abstract}
It analyzes the challenges and possibilities for the materialization of the curriculum articulated with Physical Education in Early Childhood Education, based on the dialogue with different languages, areas of knowledge and subjects of the school community. It uses Collaborative Action Research with attention to the relationships built with the pedagogical team, classroom teachers, families, children, scholarship holders of the Teaching Initiation Program, Physical Education teacher and researcher. The data from photos, interviews, narratives and field diaries were submitted to an interpretative analysis process and articulated in a network of production of meanings. It concludes that mediations with popular culture, the Institutional Project and the Physical Education Action Plan were essential gears for the materialization of curriculum engineering. As obstacles, it highlights the resistance of some teachers to collaborative work.
\end{abstract}

Keywords: Action Research; Popular culture; Child; Curriculum.

\footnotetext{
${ }^{1}$ Profa. Adjunta da Faculdade de Educação Física e Dança da Universidade Federal de Goiás (UFG), Membro do Núcleo de Aprendizagens com as Infâncias e seus Fazeres (NAIF/UFES), bethania.costa@ufg.br

${ }^{2}$ Profa. de Educação Física da Educação Infantil da Prefeitura Municipal de Vitória/ES, Membro do Núcleo de Aprendizagens com as Infâncias e seus Fazeres (NAIF/UFES), nessavix@ gmail.com

${ }^{3}$ Profa. de Educação Física do Colégio Pedro II/RJ (CPII), Membro do Núcleo de Aprendizagens com as Infâncias e seus Fazeres (NAIF/UFES), kekelfla@yahoo.com.br
} 


\section{INGENIERÍA CURRICULAR: EDUCACIÓN FÍSICA EN LA ARTICULACIÓN CURRICULAR CON EDUCACIÓN INFANTIL}

\section{RESUMEN}

Analiza los desafíos y posibilidades para la materialización del currículo articulado con la Educación Física en la Educación Infantil, a partir del diálogo con diferentes lenguajes, áreas de conocimiento y materias de la comunidad escolar. Utiliza Investigación Acción Colaborativa con atención a las relaciones construidas con el equipo pedagógico, maestros de aula, familias, niños, becarios del Programa de Iniciación Docente, docente e investigador de Educación Física. Los datos de fotos, entrevistas, narrativas y diarios de campo fueron sometidos a un proceso de análisis interpretativo y articulados en una red de producción de significados. Se concluye que las mediaciones con la cultura popular, el Proyecto Institucional y el Plan de Acción de Educación Física fueron engranajes fundamentales para la materialización de la ingeniería curricular. Como obstáculos, destaca la resistencia de algunos profesores al trabajo colaborativo.

Palabras clave: Investigación Acción; Cultura popular; Niño; Currículum.

\section{INTRODUÇÃO}

Neste artigo, analisamos a engenharia do currículo para a materialização de uma proposta articulada com a Educação Física $(\mathrm{EF})$ em interface com as linguagens, com as áreas do conhecimento e com os sujeitos da Educação Infantil (EI).

O debate sobre o currículo, na EI, revela uma preocupação comum entre os estudiosos da área, o receio de uma estrutura de organização associada à ideia de disciplinas e matérias escolares, tal como ocorre na lógica da escolarização presente no Ensino Fundamental e Médio (OLIVEIRA, 2010; BARBOSA, 2010). Contudo, com a promulgação das Diretrizes Curriculares Nacionais para a Educação Infantil (DCNEIs), das Diretrizes Curriculares Nacionais para a Educação Básica (DCNEB) e da Base Nacional Comum Curricular (BNCC) (BRASIL, 2009; 2013; 2017), evidenciou-se o acúmulo de conhecimentos que vêm sendo produzidos sobre a compreensão das formas de organização do cotidiano da EI, desde a sua inserção como primeira etapa da Educação Básica (LDB, 1996).

Nas DCNEB, o currículo da EI é entendido como “[...] práticas educacionais organizadas em torno do conhecimento e em meio às relações sociais que se travam nos espaços institucionais, e que afetam a construção das identidades das crianças" (BRASIL, 2013, p. 85). Essa organização se efetiva pelo trabalho articulado e tem como eixos estruturantes as interações e as brincadeiras. A BNCC propõe que a integração curricular, na EI, ocorra por meio dos campos de experiências desenvolvidos com as crianças, que buscam integrar as diferentes linguagens e áreas do conhecimento.

A definição de currículo explícita por esses documentos supera aquelas pautadas em 
conteúdos ou disciplinas estanques, regidas por um calendário de datas comemorativas desprovido de sentidos e valor formativo para as crianças (OLIVEIRA, 2010). De acordo com Mello et al. (2016), os campos de experiências propostos pela BNCC denotam avanços no modo de organização do trabalho pedagógico na EI, pois atribui centralidade às crianças na construção do conhecimento.

No âmbito da EF, os autores apontam para a importância do trabalho articulado com as diferentes áreas e sujeitos (MELLO et al. 2018, GUIMARÃES, 2018; ZANDOMÍNEGUE; MARTINS; MELLO, 2020). Para Sayão (2002, p. 59), a necessidade de um profissional dessa área na EI só se justifica "[...] se as propostas educativas estiverem plenamente integradas ao projeto da instituição, de forma que o trabalho dos adultos envolvidos se complete e se amplie".

Considerando que o currículo da EI não se organiza de maneira disciplinar e tampouco a criança é concebida como sujeito fragmentado, dedicamo-nos a investigar de que maneira o trabalho pedagógico da EF pode contribuir para a materialização de um currículo integrado com os diferentes sujeitos, linguagens e áreas de conhecimento, de um Centro Municipal de Educação Infantil (CMEI), localizado em Vitória/ES. Nesse percurso, quais foram os desafios e as possibilidades para a efetivação do currículo?

As análises partiram dos dados extraídos da Pesquisa-Ação Colaborativa (IBIAPINA, 2008) e evidenciaram a engenharia empreendida pela $\mathrm{EF}^{4}$ para fazer valer o propósito de implementar um currículo com a EI. Desse modo, o objetivo deste artigo é analisar os desafios e as possibilidades para a materialização do currículo articulado com a EF, na EI, a partir do diálogo com as diferentes linguagens, áreas do conhecimento e sujeitos da comunidade escolar 5 .

\section{METODOLOGIA}

Adotamos, como método, a Pesquisa-Ação Colaborativa (IBIAPINA, 2008) que sugere possibilidades de inserção no cotidiano por meio de atitudes de cooperação na produção de conhecimentos e na formação docente. O lócus desse estudo foi um CMEI situado em Vitória/ES, no período de fevereiro a dezembro de 2015. Incluímo-nos como sujeitos dessa pesquisa $^{6}$, juntamente com a professora de EF do CMEI, dez bolsistas do Pibid do curso de EF,

\footnotetext{
${ }^{4} \mathrm{~A}$ EF, neste CMEI, é representada pela professora de EF da escola, pela pesquisadora e pelos bolsistas do PIBID/EF/UFES. No texto, apresentamos ações realizadas pela EF, considerando o feito dos diferentes sujeitos que compõem esta equipe.

5 Adotamos termos como 'escola e escolares' pelo conforto da escrita, apesar de reconhecermos que as especificidades da organização da EI a diferencia da lógica escolarizante das etapas subsequentes.

${ }^{6}$ Este estudo foi aprovado pelo Comitê de Ética em Pesquisa da UFES, Parecer Consubstanciado n ${ }^{\circ}$ 1.459.317.
} 
da Universidade Federal do Espírito Santo (Pibid/EF/Ufes), 75 crianças dos grupos ${ }^{7}$ 5C, 5D e $6 \mathrm{D}$, além das professoras de sala, equipe pedagógica da escola e famílias ${ }^{8}$. Os dados produzidos, por meio de fotos, entrevistas, narrativas e diário de campo, foram submetidos a um processo de análise interpretativa e articulados em uma rede de produção de sentidos e significados. A partir desse processo, identificamos três categorias de análise: mediações com a cultura popular, a construção do Projeto Institucional e o Plano de Ação da Educação Física.

\section{A ENGENHARIA DO CURRÍCULO DA EDUCAÇÃO FÍSICA COM A EDUCAÇÃo INFANTIL}

Em nossas análises, percebemos a construção do currículo como uma engenharia sistematizada a partir da articulação com as engrenagens: cultura popular (CP), Projeto Institucional (PI) e Plano de Ação da EF (PA). Nesse sistema, as relações dialógicas se constituíram como fluido essencial para que a máquina curricular operasse. A Imagem 1 ilustra as principais engrenagens produzidas no processo de articulação da EF com a EI:

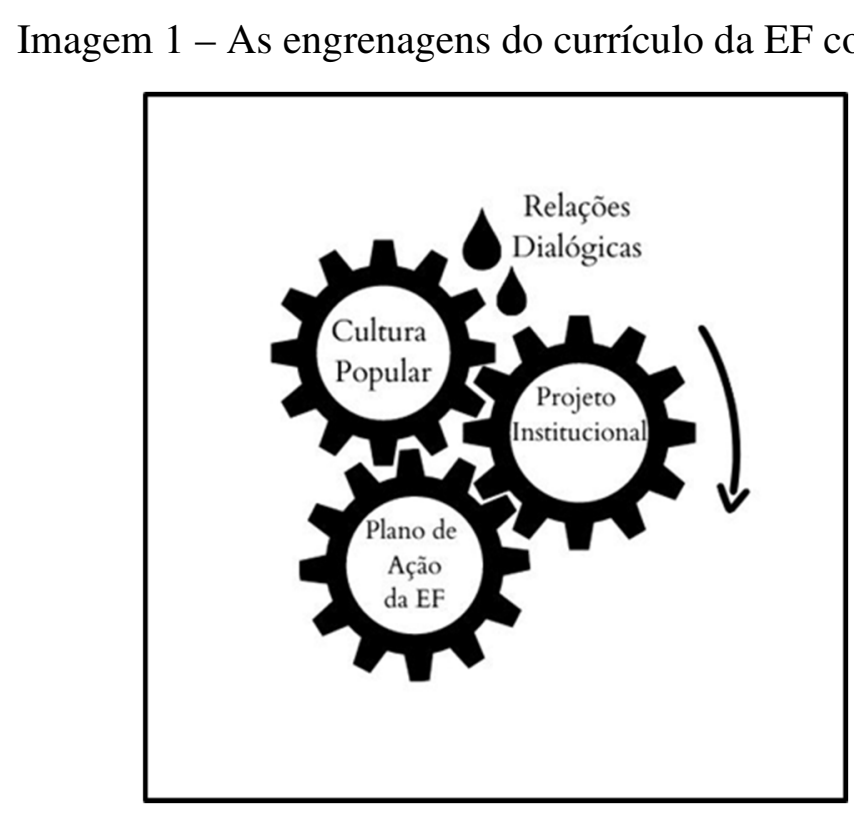

Fonte: As autoras.

\footnotetext{
${ }^{7}$ A organização das turmas, no CMEI, é estabelecida pela idade das crianças (seis meses a seis anos), que são separadas por grupos.

${ }^{8}$ Adotamos nomes fictícios e distorcemos as imagens para preservar a identidade dos sujeitos.
} 
Considerando o currículo como redes de afetos, conversações e ações complexas (CARVALHO, 2009), apresentamos a engenharia do currículo como fruto de um trabalho colaborativo da EF com as diferentes áreas e sujeitos que praticam o cotidiano da EI. A engenharia do currículo é, portanto, o estudo e a produção coletiva do conhecimento, com base nos saberes científico, econômico, social, cultural e prático, com o intuito de inventar, construir, manter, melhorar estruturas organizacionais, relacionais, sistemas e processos concernentes ao cotidiano educativo, que viabilizem a materialização de um currículo articulado.

A partir da associação a elementos que compõem uma engenharia, como máquinas, engrenagens e fluidos, as análises se deram com ênfase nos Estudos com o Cotidiano (CERTEAU, 1994), que nos permitem compreender a complexidade do contexto, com base nas práticas e representações dos sujeitos, nas relações estabelecidas entre si e o dia a dia das ações. Valorizamos a produção do conhecimento em "redes" (ALVES, 2001), onde as singularidades do cotidiano foram articuladas a um processo contínuo de produção de sentidos. A seguir, apresentaremos as engrenagens que deram dinâmica e resolubilidade às necessidades identificadas no contexto compartilhado.

\section{ENGRENAGEM 1: MEDIAÇÕES COM A CULTURA POPULAR}

Destacamos o potencial da CP como favorável à consolidação de um trabalho articulado entre as diferentes áreas que compõem o currículo. A CP valorizada nas ações didáticas da EF é aquela produzida historicamente na vida diária, no convívio com a família, a escola, o bairro e a cidade. São as formas de expressão dos diferentes "modos de ver e ser" dos sujeitos, incluindo as crianças, que geram hábitos e costumes que identificam o grupo (CERTEAU, 1994). Assim, a CP representada pelos jogos, brincadeiras, danças, músicas e outras formas de expressão revelam os sentidos e significados valorizados pelo contexto.

Partimos do pressuposto de que um trabalho pedagógico com a $\mathrm{CP}$, centrado no protagonismo da criança e nas suas produções, pode contribuir para a efetivação de uma educação integral, que atenda às especificidades da EI. Desse modo, para a materialização de um currículo articulado, buscamos diferentes recursos para estabelecer comunicação com o contexto e interagir com as crianças, elucidando práticas e culturas que comporiam nossos planos de ação.

Com as crianças adotamos as brincadeiras populares, os jogos e as danças, 
contextualizados por meio de histórias, vídeos, músicas, pinturas e desenhos. Já com os professores, a equipe pedagógica e as famílias, nos dedicamos, conforme Certeau (1994), a perceber as "culturas ordinárias" praticadas naquele contexto, os "modos de ser" e "fazer" o cotidiano, a fim de identificar meios de estabelecer comunicação com essas práticas.

Dentre as ações operacionalizadas pela EF estão a aproximação ao universo lúdico das culturas infantis, a participação em reuniões pedagógicas, o envolvimento com as famílias e o diálogo com as professoras de sala, conforme pode ser observado na Imagem 2.

Imagem 2 - Aproximação ao universo lúdico das crianças, aos sujeitos escolares e famílias.

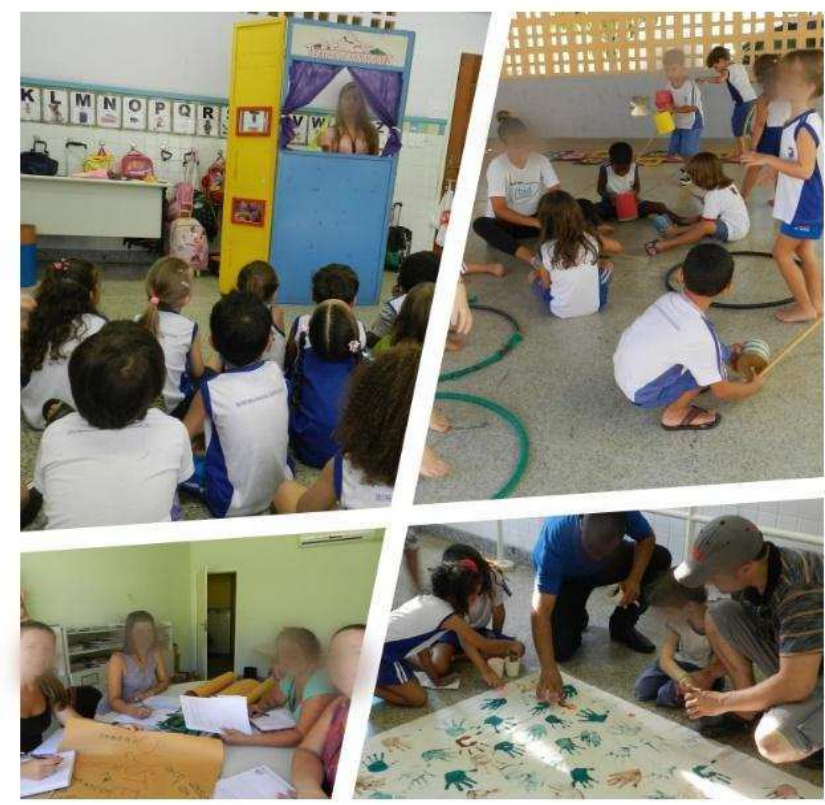

Fonte: As autoras.

Para pensar nas engrenagens de um currículo não fragmentado na EI, Sayão (2002) e Ayoub (2001) apontam para uma perspectiva que contemple as diferentes áreas do conhecimento e linguagens nas suas múltiplas formas de articulação e considere a criança como “ponto de partida”. Buss-Simão (2005, p.166) afirma que o início “[...] deve ser o interesse que as crianças demonstram em suas experiências de movimento realizadas espontaneamente, assim como nos fenômenos da cultura popular da qual fazem parte".

É nesse sentido que nossas ações foram empreendidas, dedicando atenção às crianças, aos seus anseios e produções culturais. As estratégias pedagógicas oriundas desse cuidado foram potencializadas pela mediação com a CP. Nas narrativas seguintes é possível observar a $\mathrm{CP}$ como engrenagem essencial à dinâmica do currículo, considerada pelas docentes como 
canal facilitador de articulação, carregado de sentidos e significados para as crianças e a comunidade.

Na EI, a música, a brincadeira [...] é fundamental para nossa comunicação com a criança e para a comunicação dela nesse espaço. [...] Além de interessante para o nosso trabalho aqui dentro do CMEI, as temáticas da cultura popular são fundamentais e urgentes, hoje (ROSA - professora do Grupo 5C).

Quando você lida com a cultura popular, abre-se um leque muito ampliado de recursos para se atingir as diferentes linguagens. São oportunidades muito ricas. Ao mesmo tempo em que se traz uma cultura do seu Estado para o CMEI, se resgata a cultura da história da criança e, a partir de uma fusão desses elementos pela mediação, se amplia a cultura popular (GRASI - professora de EF).

Com base nessas narrativas, é possível perceber que, ao serem incorporados ao processo educativo, os diálogos com a CP permitem implementar ações colaborativas que favorecem o desenvolvimento pleno do indivíduo, superando, na prática, a lógica fragmentada e disciplinar na produção do conhecimento.

$\mathrm{Na}$ engenharia do currículo aqui empreendida, as inter-relações com a CP incorporaram saberes, que se estabeleceram nas experiências vividas, nas trocas e negociações que dinamizaram o processo ensino/aprendizagem. Em um fluxo dinâmico de acordos e desacordos, as culturas e o currículo foram se constituindo na associação com outras engrenagens, como objetos de interação e conhecimento pelas crianças, e nas manifestações e tradições culturais brasileiras.

\section{ENGRENAGEM 2: A CONSTRUÇÃO DO PROJETO INSTITUCIONAL}

A execução dessa engrenagem se estabeleceu a partir da articulação entre diferentes sujeitos: as docentes do CMEI, a equipe gestora, a professora de EF, a pesquisadora e as crianças. Nesse universo de interlocutores, a EF protagonizou ações, considerando os pressupostos que orientavam a sua intenção de colaborar para a implementação de um trabalho articulado.

Pensando nas engrenagens como algo que prospectiva movimento, a EF se empenhou em estabelecer parcerias com a comunidade escolar e contribuir para a retomada do PI. Pesquisas como a de Jorge e Mello (2013) e Zandomínegue, Martins e Mello (2020) discutem a potencialidade do PI como eixo articulador do trabalho pedagógico da EF com a El. Almeida (2002, p. 58) corrobora essa ideia destacando que, 
O projeto rompe com as fronteiras disciplinares, tornando-as permeáveis na ação de articular diferentes áreas de conhecimento, [...]. Isso não significa abandonar as disciplinas, mas integrá-las [...], aprofundando-as verticalmente em sua própria identidade, ao mesmo tempo, que estabelecem articulações horizontais numa relação de reciprocidade entre elas, a qual tem como pano de fundo a unicidade do conhecimento em construção.

No contexto compartilhado, o PI é considerado, por muitas docentes, como o eixo condutor para o diálogo entre as diferentes áreas que compõem o currículo. Pode-se observar essa questão nos trechos de entrevistas realizadas com as professoras:

O Projeto Institucional é o gancho, um suporte pra gente trabalhar. Ele que dá o norte pra aquilo que a gente quer desenvolver na sala de aula e no CMEI (CARMEM - professora do Grupo 5D).

Eu acredito no Projeto Institucional para dar o gancho com o projeto de sala [...]. Eu consegui articular com Artes e EF e foi muito positivo ver o resultado dessa ação nas crianças (LAURA - professora do Grupo 6D).

No processo de fabricar esta engrenagem, evidenciamos momentos em que houve uma participação mais incisiva das docentes, se constituindo como efetivas "redes" de colaboração (ALVES, 2001). Entretanto, em ocasiões em que as professoras não se viam como "autoras" das ideias trazidas, as redes não se efetivaram. Algumas docentes resistiram à implementação do PI, o que foi observado como principal entrave dessa engrenagem e gerou dificuldades de pensar de modo coletivo, conforme observado nos seguintes trechos:

A professora de EF nos contou sobre a reunião que os professores e pedagogos fizeram com cada turno. No matutino, discutiu-se qual seria o painel para o Projeto Institucional [...]. Entretanto, no turno vespertino, as pedagogas não conseguiram fazer a transição da ideia aprovada na reunião da manhã. Algumas professoras que atuam há mais tempo na escola não acataram a sugestão [...]. Constatamos que [...] [a ideia] simbolizava outros contextos não protagonizados por algumas delas que manifestaram resistência à proposta (DIÁRIO DE CAMPO, 16-4-2015).

Eu não queria trabalhar o projeto institucional porque eu achava que a gente já tinha tido experiências negativas e acho que o profissional que faz esse gancho é fundamental para que esse trabalho seja desenvolvido [...]. (ROSA - professora do Grupo 5C).

Para superar esses limites e colaborar para a efetivação de um trabalho coletivo, a EF agiu nas "brechas" (CERTEAU, 1994). As análises e discussões fomentadas com a equipe pedagógica geraram encaminhamentos com o grupo macro. O intuito foi sensibilizar os gestores quanto à importância de um trabalho articulado entre as áreas e sujeitos. Destacamos as 
contribuições da EF para mediar e conduzir as ideias trazidas/captadas nos/pelos diferentes segmentos, especialmente pelo fato da professora atuar nos dois turnos do CMEI.

Um dos recursos essenciais foram as conversas com o "miudinho", consideradas como fluidos potenciais para a operacionalidade das engrenagens do currículo. De modo estratégico e intencional, nas conversas informais, a EF indicava possibilidades de ações colaborativas. Como consequência dessas trocas, as professoras se sentiram motivadas a compor ações com a $\mathrm{EF}$, conforme evidenciado em nosso diário de campo:

No corredor, ao passar uma pela outra, a professora do Grupo 6D disse à professora de EF: '- Que dia podemos conversar para planejarmos uma ação conjunta no projeto? [...]’. (DIÁRIO DE CAMPO, 20-8-2015).

Recursos como imagens, vídeos, textos, poesias e músicas também foram utilizados nas reuniões pedagógicas para promover reflexões acerca das propostas colaborativas. O clipe da música 'A nossa casa', de Arnaldo Antunes, foi a "peça-chave" para aguçar ideias para o projeto. A música também inspirou o nome do PI, 'A nossa casa é onde a gente está, a nossa casa é em todo lugar'.

Apesar dos desafios, ao compartilharem suas sugestões e experiências com o grupo, as professoras, a equipe pedagógica e a EF tiveram participações fundamentais materializando uma rede de colaborações. A participação das crianças na construção do PI ocorreu por meio das mediações das professoras, nas suas ações pedagógicas que, posteriormente, eram compartilhadas nas reuniões. $\mathrm{O}$ interesse de envolver a comunidade escolar na construção do currículo sinalizou um avanço na maneira de o CMEI propor diálogo com os segmentos, observando e refletindo conjuntamente sobre as redes complexas de colaborações, que são tecidas com os fios da experiência coletiva.

Essa ação denota outra lógica de construção de currículo na EI, ou seja, um currículo constituído por tudo aquilo que é " [...] vivido, sentido, praticado no âmbito escolar e que está colocado na forma de documentos escritos, conversações, sentimentos, ações concretas vividas pelos praticantes do cotidiano" (CARVALHO, 2009, p. 179).

Assim, o PI se consolidou a partir das tensões, afetos e diálogos entre as áreas, formando uma rede de produção de conhecimentos. Isso permitiu perceber o protagonismo dos diferentes sujeitos, sobretudo ao compartilhar suas experiências e ideias com o grupo. Cada qual, à sua maneira, compôs essa relação pedagógica e coletiva, constituinte da engenharia do currículo. 


\section{ENGRENAGEM 3: O PLANO DE AÇÃO DA EDUCAÇÃO FÍSICA}

Ao assumir o projeto da EF como uma engrenagem, afirmamos sua importância na composição de um sistema que produz dinâmica ao currículo da EI. Nesse contexto, a criança e suas experiências são o "ponto de partida", fundamentado numa concepção de criança cidadã,

sujeito de direitos e uma educação centrada no seu protagonismo. É como afirma Sarmento (2015, p. 81), “[...] partir das crianças e das práticas culturais para organizar a ação pedagógica: eis o princípio da ação".

Na elaboração e desenvolvimento do PA da EF, tomamos como referência os pressupostos da Sociologia da Infância, que concebe a criança como produtora de cultura, com participação ativa nos seus processos de socialização e aprendizagem (SARMENTO, 2015; CORSARO, 2011). Reconhecendo as interações e brincadeiras como eixos estruturantes dos processos educativos desenvolvidos com as crianças (BRASIL, 2009), a estratégia inicial da EF foi captar os elementos das "culturas de pares" (CORSARO, 2011) valorizadas no cotidiano. Dessa forma, empreendeu-se uma série de ações para a produção de conhecimentos com as crianças.

Para potencializar nosso diálogo com elas e captar suas preferências acerca das brincadeiras populares, deixamos que escolhessem atividades para vivenciar no pátio. Assumimos, uma atitude de observação participante e interagimos com as crianças. Dedicamonos a captar suas práticas de comunicação no movimento da sua "enunciação", que é a fala em ato (CERTEAU, 1994). Pelas enunciações percebemos as brincadeiras que lhes despertavam maior interesse. Também buscamos conhecer suas identificações por meio de desenhos. $\mathrm{Na}$ Imagem 3, é possível visualizar os desenhos e brincadeiras das crianças como cabo de guerra, cabra-cega, amarelinha e bambolê. Essas e outras pistas constituíram condições elementares para o nosso propósito de elaborar um PA com a valorização dos interesses e da participação delas. 
Imagem 3 - Desenhos e brincadeiras das crianças

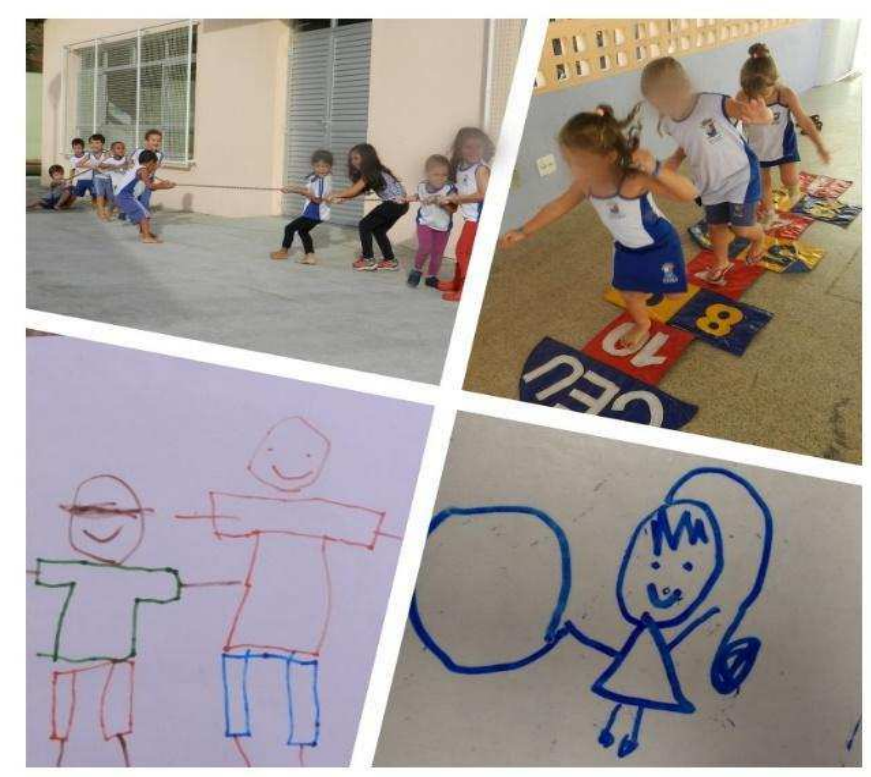

Fonte: As autoras.

As enunciações e memórias lúdicas captadas pelas narrativas das crianças, ante as mediações com as brincadeiras, funcionaram como uma alavanca, que permitiu produção de sentidos e trouxe movimento à máquina, a da prática pedagógica da EF. A escuta e o diálogo empreendidos aproximaram o pouco que conhecíamos a respeito dos contextos culturais delas e o manancial de experiências que traziam.

De acordo com Sayão (2002), pela representação, é possível identificar as vivências do sujeito e também aspectos que indicam a cultura na qual ele é formado. Representar, seja oralmente ou através do desenho, é uma forma de trazer o espaço cultural como um meio singular e universal, já que, quando representa, o indivíduo o faz a partir de vivências próprias. Nesse contexto, a estratégia de nos aproximarmos das crianças por meio da identificação e diálogo com suas brincadeiras foi a "porta de entrada" para um universo de informações que nos trouxe "pistas" do itinerário que poderíamos construir juntos, em interface com o PI.

O PI inspirou a sistematização de dois blocos temáticos para o PA da EF: 1) A nossa casa é onde a gente está; e 2) A nossa casa é em todo lugar. Em cada bloco, houve a distribuição de eixos de mediação: a) casa-corpo; b) casa-lar; c) casa-escola; d) casa-bairro; e) casa-cidade.

O primeiro bloco, 'A nossa casa é onde a gente está', abordou a temática "casa", associada ao corpo, ao lar e à escola. Desse modo, foram contemplados os eixos: a) casa-corpo, que desenvolveu aspectos relacionados com a consciência, percepção e expressão corporal; b) casa-lar, que problematizou sobre o cotidiano de brincadeiras das crianças, as práticas culturais 
do grupo familiar e os hábitos sustentáveis; e c) casa-escola, que desenvolveu o reconhecimento do CMEI como parte de suas casas e estimulou a variação das formas de brincar no CMEI, envolvendo a participação das famílias e comunidade.

O segundo bloco do PA da EF, 'A nossa casa é em todo lugar', focalizou a ampliação das experiências das crianças com as culturas e as questões ambientais para além do CMEI. Assim, o eixo: d) casa-bairro explorou o conhecimento do entorno, as ruas, as praças e os parques. Por fim, e) casa-cidade extrapolou as vivências das crianças na escola e no bairro, avançando para outros lugares/espaços da cidade, como praias e parques.

No diálogo com as linguagens e sujeitos, a EF perspectivou educar com e para a cultura. Nessa engenharia, as aulas foram ministradas pela professora do CMEI, pelos bolsistas do Pibid/EF/Ufes e pela pesquisadora. Cada mediação era precedida de planejamento. Debatíamos questões observadas no campo e encaminhávamos novas ações. Inferimos que a presença do $\mathrm{Pibid} / \mathrm{EF} / \mathrm{Ufes}$ e mediações com a CP trouxeram movimentações diferentes à dinâmica curricular, dado o contingente de pessoas e conteúdos/temáticas ${ }^{9}$, que nos permitiram inovar pedagogicamente. Como resultado, observamos um redimensionamento do olhar da comunidade escolar para a EF. As narrativas da professora de sala e do bolsista evidenciam essa questão:

O que eu posso falar deste ano é que a EF foi fantástica para elas [crianças]. E o desenvolvimento delas foi muito legal. Acho que a questão do Pibid ter vindo trouxe "gás", vida, experiências novas. [...] O que a família viu do desenvolvimento das crianças [...] só trouxe relatos positivos [...] da EF, do projeto coletivo [...]. Conseguimos fazer chegar em casa isso e [...] ter esse retorno positivo [...]. (ROSA - professora do Grupo 5C).

O trabalho que a gente fez e mostrou para a comunidade foi elogiado pelos pais das crianças, professores [...]. Isso mostra que houve reconhecimento pelo esforço que empreendemos (BOLSISTA D. - Pibid/EF/Ufes).

A observação desses dados, associada às experiências compartilhadas, oferecem pistas de uma representação favorável ao trabalho da EF e denotam a importância dessa área de conhecimento na EI, especialmente, para a materialização de um currículo articulado com as experiências corporais das crianças. Conforme Crusoé (2004), a inserção de um "objeto novo" provoca uma modificação no universo representacional do sujeito. Isso varia conforme a relevância desse objeto e seu interesse para o grupo. A engrenagem construída a partir das ações colaborativas da EF com o Pibid/EF/Ufes e as crianças se constituíram como "objeto novo", de transformação daquela realidade.

\footnotetext{
${ }^{9}$ Conhecimentos oriundos da cultura popular, como histórias, músicas, jogos e brincadeiras.
} 


\section{CONSIDERAÇÕES FINAIS}

A realização desse estudo, que teve como objetivo analisar os desafios e as possibilidades para a materialização do currículo articulado na EI, evidenciou a importância da EF na consolidação de um trabalho estabelecido com as experiências corporais das crianças.

Operamos na construção de uma engenharia formada a partir de um sistema de engrenagens que viabilizassem ações colaborativas entre sujeitos e áreas. As mediações com a CP evidenciaram o seu potencial para a articulação com as crianças e a comunidade, dada a diversidade de ações e sentidos que esses saberes promovem. Apesar dos entraves para a construção do PI, como a resistência de algumas docentes, o interesse de envolver a comunidade sinalizou um avanço na maneira de o CMEI propor a construção do currículo.

Salientamos que, para o desenvolvimento de suas ações pedagógicas, é importante que a EF atue, na EI, por meio de um PA que dialogue com o PI, considerando as culturas infantis. Contudo, as experiências, aqui compartilhadas, explicitam um cotidiano vivido e não necessariamente se aplicam a outros. Algumas dessas operações foram previamente planejadas; outras se constituíram ou se ressignificaram na efemeridade do contexto. Na engenharia do currículo, o diálogo se constituiu como elemento essencial para promover a mobilidade e para superar os desafios decorrentes da própria conjuntura organizacional da EI, que nem sempre assegura tempo e espaço para o planejamento integrado.

Desse modo, concluímos que princípios da engenharia ofereceram subsídios para pensar o currículo, motivando os sujeitos dessa pesquisa para um processo de interpretação do cotidiano, no que tange à necessidade de mudanças e de criações relacionadas às práticas pedagógicas neste CMEI.

\section{REFERÊNCIAS}

ALMEIDA, M. E. B. Como se trabalha com projetos. Revista TV Escola. Secretaria Educação Distância, Brasília: Ministério Educação, n. 22, mar./abr. 2002.

ALVES, N. Decifrando o pergaminho: o cotidiano das escolas nas lógicas das redes cotidianas. In: OLIVEIRA, I. B.; ALVES, N. (Org.). Pesquisa no/do cotidiano das escolas: sobre redes de saberes. Rio Janeiro: DP\&A, 2001. p.13-37.

AYOUB, E. Reflexões sobre a educação física na educação infantil. Revista Paulista Educação Física, São Paulo, supl. 4, p. 53-60, 2001.

BARBOSA M. C. S. Os resultados da avaliação de propostas curriculares para a educação infantil dos municípios brasileiros. I SEMINÁRIO NACIONAL: currículo em movimento: perspectivas atuais. 
2010, Belo Horizonte. Anais..., Belo Horizonte: nov. 2010.

BRASIL. Lei n ${ }^{\circ}$ 9.394, 20 dezembro 1996. Estabelece as diretrizes e bases da educação nacional. Diário Oficial [da] República Federativa do Brasil, Brasília, DF, v. 134, n. 248, 23 dez. 1996. Seção I, p. 27834-27841.

. Ministério Educação. Conselho Nacional de Educação. Diretrizes Curriculares Nacionais para a Educação Infantil. Brasília/DF, 2009.

. Secretaria Educação Básica. Revisão das Diretrizes Curriculares Nacionais para a Educação Infantil. Diretrizes Curriculares Nacionais Gerais da Educação Básica, Brasília: MEC, SEB, Dicei, 2013. p. 80-101.

Base Nacional Comum Curricular. 3. vers. Ministério Educação. Brasília: MEC, 2017.

BUSS-SIMÃO, M. Educação física na educação infantil: refletindo sobre a "hora da educação física." Motrivivência, Florianópolis, n. 25, p. 163-173, Jan. 2005.

CARVALHO, L. D. Infância, brincadeira e cultura, UFMG GT-07: educação de crianças de 0 a 6 anos. Agência Financiadora: CNPq. Horizontes, v. 27, n. 2, jul./dez. 2009.

CERTEAU, M. A invenção do cotidiano: artes de fazer. Petrópolis: Vozes, 1994.

CORSARO, W. Sociologia da infância. Porto Alegre: Artmed, 2011.

CRUSOÉ, N. M. C. A teoria das representações sociais em Moscovici e sua importância para a pesquisa em educação. Aprender: Cad. Filosofia e Psic. Educação. Vitória Conquista, ano II, n. 2, p. 105-114, 2004.

GUIMARÃES, V. Dinâmica Curricular no cotidiano da Educação Infantil: um olhar a partir das práticas pedagógicas com a Educação Física. 2018. 217f. Dissertação (Mestrado em Educação Física) - Programa de Pós-Graduação em Educação Física, Universidade Federal do Espírito Santo, Vitória, 2018.

IBIAPINA, I. M. L. M. Pesquisa colaborativa: investigação, formação e produção de conhecimentos. Brasília: Líber Livro Editora, 2008.

JORGE, R. S.; MELLO, A. S. Análise do projeto institucional como mediador para a intervenção da educação física na educação infantil. In: HOFMANN, A.; VOTRE, S. J. Esporte e educação física ao redor do mundo: passado, presente e futuro. Rio de janeiro: Editora Gama Filho, 2013. p. 247-263.

MELLO, A. S. et al. A educação infantil na Base Nacional Comum Curricular: pressupostos e interfaces com a educação física. Motrivivência, v. 28, n. 48, p. 130-149, set. 2016.

MELLO, A. S. et al. Educação Física na Educação Infantil: do isolamento pedagógico à articulação com outras áreas do conhecimento, Revista Kinesis, v. 36, n. 3, p. 15-27, set.-dez. 2018.

OLIVEIRA, Z. M. R. O currículo na educação infantil: o que propõem as novas diretrizes nacionais? I SEMINÁRIO NACIONAL: currículo em movimento: perspectivas atuais. 2010, Belo Horizonte.

Anais..., Belo Horizonte: nov. 2010.

SARMENTO, M. J. Para uma agenda da educação da infância em tempo integral assente nos direitos da criança. In: ARAÚJO, V. C. [et al.] (org.). Educação infantil em jornada de tempo integral: dilemas e perspectivas. Vitória: EDUFES, 2015. p. 61-89.

SAYÃO, D. T. Corpo e movimento: notas para problematizar algumas questões relacionadas à educação infantil e à educação física. RBCE, Campinas, v. 23, n. 2, p. 55-67, jan. 2002.

ZANDOMÍNEGUE, B. A. C.; MARTINS, R. L. D.; MELLO, A. S. A Educação Física na articulação curricular com a Educação Infantil. Rebescolar, ano v, v. 3, p. 100-118, març. 2020. 